\title{
Interpretação constitucional pós-positivista
}

\author{
Márcia dos Santos Eiras ${ }^{1}$
}

\section{Resumo}

Este artigo trata da interpretação constitucional, resgatando, inicialmente, seu desenvolvimento histórico até a interpretação pós-positivista, como é aceita enquanto nova perspectiva do Direito. Foca na importância dos princípios como portadores de aplicabilidade direta nos conflitos, com fim de solidificar uma interpretação concretizadora por parte dos operadores e reintroduzir as idéias de justiça e legitimidade ao ordenamento jurídico.

Palavras-Chave: Princípios constitucionais; Pós positivismo; Princípios instrumentais; Princípios materiais; Dignidade da pessoa humana.

\section{Introdução}

Ao se interpretar o processo de entendimento do Direito como elemento organizador da sociedade e instituto de coerção único e oficial, notam-se três fases distintas cuja interdependência é clara.

Primeiro, houve a fase metafísica na qual o Direito era visto com uma origem transcendente, ou seja, como oriundo de um mundo ideal ou de um ser etéreo aos moldes da noção de "direito divino" como defendeu Bodin e Santo Tomás de Aquino.

Nesta fase, o Direito vinculava-se com uma característica de determinabilidade intransigente de ações, obrigações e deveres sem que houvesse qualquer discussão do homem como sujeito "produtor" das normas em questão.

Em segundo lugar, houve a ascensão da perspectiva cientificista pautada na fase "positivista", quando o direito, seguindo a noção da capacidade do homem de construir o mundo que o cerca conforme a razão, passa a se relacionar especificamente com o processo de construção normativa e respectiva aplicação na sociedade.

\footnotetext{
1 Pós-graduada em Direito Civil e Processo Civil e Direito Empresarial pela Universidade Estadual de Londrina, Advogada e Professora de Direito Civil na Faculdade Dom Bosco de Cornélio Procópio - Paraná.
} 
É exatamente por este viés que ascende o ideário de uma leitura essencialmente "científica" do Direito, revelando a noção de uma construção normativa sob a égide imutável do princípio da legalidade.

Em terceiro lugar, pensadores do Direito comentam a existência de uma fase "póspositivista" em que, apesar das leis, decretos e normas serem elementos imprescindíveis para a construção do Direito, são os princípios que assumem papel fundamental, colocando de lado uma perspectiva dogmática presa nas normas programáticas.

\begin{abstract}
A normatividade dos princípios percorreu três fases distintas: a jusnaturalista, a positivista e a pós-positivista. Na primeira, os princípios estavam fora do direito, em um campo metafísico, associados à dimensão ético-valorativa inspiradora do direito.Na fase positivista, os princípios ingressaram nos códigos e leis como fonte normativa subsidiária com a função de garantir a inteireza e coesão do sistema. Por fim, a fase pós-positivista atual, na qual os princípios constitucionais têm um papel fundamental, consagra os princípios não apenas como direito, mas como "pedestal" normativo sobre o qual assenta todo o edifício jurídico dos novos sistemas constitucionais (GUIMARÃES, 2006).
\end{abstract}

É exatamente em torno das relações contraditórias e complementares entre a segunda fase (positivista) e a terceira (pós-positivista) que giram as principais discussões sobre a aplicação correta da norma em relação a contratos e outras posições jurídicas nos dias atuais.

O pós-positivismo não surge com o ímpeto da desconstrução, mas como uma superação do conhecimentos convencional. Ele inicia sua trajetória guardando deferência relativa ao ordenamento positivo, mas nele reintroduzindo as idéias de justiça e legitimidade (BARROSO, 2003, p. 72).

A fase pós-positivista, ao defender a aplicação dos princípios como fundamentos imprescindíveis do processo normativo, na verdade, está promovendo uma diferenciação de interpretação do processo de entendimento do Direito. É notório que, uma leitura antiga do Direito, não achava possível uma decisão legal apenas fundamentada em princípios, dizendo que a presença desses, em relação às normas, era de fundamentos "abstratos" na construção do Direito. 


\section{Novo paradigma}

Esta leitura "positivista", como acima mostrado, por uma corrente extremamente científica, qualificava os princípios como meras figuras alegóricas que, na prática, eram freqüentemente esquecidos diante das decisões totalmente fundamentadas no que a norma determinava claramente ou não. Seguindo esta forma de interpretação do direito, comenta Canotilho (1998, p. 1045):

Enquanto um direito constitucional pode ser directamente invocado em tribunal como justificativo de um recurso de direito público, já a inobservância de um princípio é considerada insusceptível de, por si só, fundamentar autonomamente um recurso contencioso. Seria, por exemplo, difícil fazer valer uma pretensão em tribunal invocando-se tão somente o princípio da proporcionalidade. Os princípios fundamentais, fornecendo embora directivas jurídicas para uma correta análise dos problemas constitucionais, não possuem normatividade individualizadora que os torne suscetíveis de aplicação imediata e autônoma.

O autor claramente define os princípios como sendo elementos de valor imprescindível para o Direito, no entanto os classifica como "diretivas jurídicas" que, para terem validade na prática do Direito, devem ser instrumentalizadas pelas normas constitucionais positivamente vigentes.

Esta interpretação positivista valorizava as normas como elementos de caráter programático, ou seja, como construções legais cujo valor estava relacionado com um resultado previamente estabelecido e "juridicamente" esperado.

Juristas, na atualidade, revelam exatamente que esta situação das normas jurídicas as desvincula de uma relação de validade social, sendo que, ao se usar o termo "normas programáticas" acaba-se pensando em normas "fins" ou normas "resultados", jogando-as a um espaço meramente técnico.

Por isso, Canotilho (2000, p. 1060), na Edição Atualizada da mesma obra supra citada, revela uma clara mudança de seu pensamento em relação aos princípios mas, principalmente, em virtude das modificações que a sociedade sofreu focalizando uma atuação mais dinâmica e direta dos princípios:

Hoje não há normas constitucionais programáticas. É claro que continuam a existir normas-fim, normas-tarefa, normas-programa que 'que impõem uma actividade' e 'dirigem' materialmente a concretização constitucional. Mas o sentido destas normas não é o que lhes assinalava tradicionalmente a doutrina: 'simples 
programas', 'exortações morais', 'declarações', 'sentenças políticas', aforismos políticos', 'promessas', 'apelos ao legislador', 'programas futuros', juridicamente desprovidos de qualquer vinculatividade. Às 'normas programáticas' é reconhecido hoje um valor jurídico constitucionalmente idêntico ao dos restantes preceitos da Constituição. Mais do que isso: a eventual mediação da instância legiferante na concretização das normas programáticas não significa dependência deste tipo de normas da interposição do legislador; é a positividade das normas-fim e normastarefa (normas programáticas).

As propostas pós positivistas fundamentam que uma "norma" vista apenas como uma regra de obrigação vinculada a fins "programáticos" não pode ser elemento de construção normativa coerente com o contexto da sociedade, sendo fundamental a presença dos princípios que devem ser considerados como partículas construtoras das ações de Direito e não apenas figuras de embasamento teórico ou de característica somente de cunho complementar.

Assim, a doutrina atual tende a criar a aplicação dos princípios diretamente em situações contenciosas, usando dois termos claros: "normas-regras" e "normas-princípios".

As normas-regras referem-se às leis com seu caráter programático indiscutível ficando aos moldes das perspectivas positivistas anteriormente comentadas, enquanto as normas-princípios são aquelas exatamente vinculadas com os princípios do Direito, como o respeito pela dignidade humana ou a noção de proporcionalidade, que se tornam "leis" a serem cumpridas e cuja aplicabilidade diretamente se dá na prática contemporânea.

\footnotetext{
Tornou-se comum mencionar na boa doutrina que as normas jurídicas são compostas de normas-regras e normas-princípios, assim, sem embargos de já não subsistir a divergência no que tange a noção de que princípios e regras são tipos de normas, ambos dotados de imperatividade (GUIMARÃES, 2006).
}

Para Paulo Bonavides (2001), a novidade da teoria pós positivista do Direito se refere exatamente à construção de elementos normativos vinculados à colocação de princípios na própria prática jurídica.

A hegemonia dos princípios significa a extensão da órbita pública do Direito compondo uma necessária proposta de interpretação fundada necessariamente na relação entre o direito e seu vínculo com as práticas sociais básicas. 
Princípios e Regras passam a habitar um mesmo referencial, ambos sendo, portanto, partículas de aplicabilidade normativa, ou seja, regras conceituadas e válidas, sem a presença de qualquer hierarquia teórica entre si.

\begin{abstract}
A teoria dos princípios chega à presente fase do pós-positivismo com os seguintes resultados já consolidados: a passagem dos princípios da especulação metafísica e abstrata para o campo concreto e positivo do Direito, com baixíssimo teor de densidade normativa; a transição crucial da ordem jusprivatista (sua antiga inserção nos Códigos) para a órbita juspublicística (seu ingresso nas Constituições); a suspensão da distinção clássica entre princípios e normas; o deslocamento dos princípios da esfera da jusfilosofia para o domínio da Ciência Jurídica; a proclamação de sua normatividade; a perda de seu caráter de normas programáticas; o reconhecimento definitivo de sua positividade e concretude por obra sobretudo das Constituições; a distinção entre regras e princípios como espécies diversificadas do gênero norma; e, finalmente, por expressão máxima de todo esse desdobramento doutrinário, o mais significativo de seus efeitos: a total hegemonia e preeminência dos princípios (BONAVIDES, 2001, p. 294).
\end{abstract}

Percebe-se, então, que uma das grandes mudanças empreendidas pelo direito, visto pelo âmbito pós positivo, é exatamente a ascensão da releitura do princípio da eficácia que, anteriormente, estava relacionado exclusivamente às regras de aplicabilidade normativa.

A eficácia não é mais o resultado conseqüente do processo de construção do Direito a partir das regras devidamente positivadas, mas passa a se relacionar com os resultados materiais consagrados pela relação construtiva entre regra oriunda de lei ou outra oriunda apenas de princípios.

Deste modo, é necessário propor uma re-interpretação normativo-funcional do direito que é parte intransigente da cultura que se relaciona às partes interessadas e às mudanças sociais que, a todo instante, giram em torno da noção de "legal" e de "justo".

Para Ana Paula Barcellos (2002, p. 82) os princípios assumiram certamente a posição de regras de aplicabilidade e é exatamente esta característica que constitui o núcleo da noção de direito pelo âmbito pós positivo.

Toda vez, portanto, que houver uma situação que contrarie os princípios do Direito, na verdade, se está falando em uma situação que fere a noção pública de segurança e eficácia constitucional, dando margem exatamente para uma decisão pautada no princípio como regra aplicável. 
Sendo assim, o direito pós positivo pode ser entendido justamente como o ato de gerir socialmente o direito que é baseado em ações dirigidas pelos fundamentais princípios constitucionais em um sentido amplo.

Os princípios constitucionais são vistos não apenas como substâncias fixas, base das normas constitucionais, mas, necessariamente, são qualificados como veículos da mais pura e direta participação ativa nas situações contenciosas e na defesa dos direitos individuais e particulares dos cidadãos.

Vezio Crisafulli (apud OLIVEIRA, 2006) define este novo paradigma do direito no âmbito pós-moderno como sendo a percepção exata dos princípios como elementos com "acepção" contextual de positiva aplicabilidade, ou seja, como atuando diretamente no direito em decorrência de inúmeras qualidades especiais.

Este autor (CRISAFULLI apud OLIVEIRA, 2006) diz que o princípio consegue obter o status de atuação jurídica em virtude de ser válido para todos os homens conforme as seguintes qualidades:

a) A justiça detém comuns princípios de aplicabilidade que são indiscutíveis e válidos em toda situação de lide jurídica (generalidade);

b) Os princípios são os primeiros que devem ser tomados para a solução de conflitos humanos devido à sua característica de "construtor" dos valores normativos (primariedade);

c) Todo princípio só tem atividade jurídica em decorrência do respeito pela dignidade humana e pela capacidade do homem de dar sentido próprio às coisas (dimensão axiológica);

d) Os princípios criam obrigações e respeito como se fossem regras objetivas (objetividade);

e) Os princípios nascem da construção racional do homem e não provêm de uma determinação "divina” ou "dogmática” (transcendência);

f) Os princípios sempre são válidos em qualquer situação histórica conforme o contexto normativo (atualidade);

g) Os princípios mudam, adaptando-se em busca de uma eficácia social positiva (poliformia); 
h) Os princípios se vinculam tanto a regras normativo-constitucionais, quanto ao anseio de fazer justiça do poder judiciário, relacionando-se totalmente com o caso específico em discussão (vinculabilidade);

i) Os princípios aderem tanto à norma, quanto à vontade do jurista e das partes envolvidas em busca de uma reunificação do consenso jurídico e eficaz (aderência);

j) Os princípios informam as partes sobre resultados pleiteados e sobre os fundamentos de respeito pela dignidade humana e pela noção de justiça próprios da construção do Estado de Direito (informatividade);

I) Os princípios não atuam como verdades absolutas, buscando, a todo instante, uma complementação técnico-normativa, bem como relação complementar com os anseios sociais (complementaridade);

m) Apesar de não serem "regras" no sentido programático, a força dos princípios, em virtude de todos esses parâmetros, é exatamente relacionado a uma norma (normatividade).

Princípio é, com efeito, toda norma jurídica, enquanto considerada como determinante de uma ou de muitas outras subordinadas, que a pressupõem, desenvolvendo e especificando ulteriormente o preceito em direções mais particulares (menos gerais), das quais determinam e, portanto, resumem, potencialmente, o conteúdo sejam [...] estas efetivamente postas, sejam, ao contrário, apenas dedutíveis do respectivo princípio geral que as contêm. Desta conceituação é possível se extrair as seguintes características dos princípios do direito: a) generalidade; b) primariedade; c) dimensão axiológica; d) objetividade; e) transcendência; f) atualidade; g) poliformia; h) vinculabilidade; i) aderência; j) informatividade; I) complementaridade; e m) normatividade (CRISAFULLI apud OLIVEIRA, 2006).

Podem ser elencados, no campo teórico pós-positivista, dois pilares básicos: a proposta de uma nova grade de compreensão das relações entre direito, moral e política; e o desenvolvimento de uma crítica contundente à concepção formalista do positivismo jurídico. Em relação a este segundo aspecto, interessa frisar a emergência de um modelo de compreensão principiológica do direito, que confere aos princípios jurídicos uma condição central na estruturação do raciocínio do jurista, com reflexos diretos na interpretação e aplicação da ordem jurídica (NERY, 2002, p. 30). 


\section{Princípios instrumentais}

Após a demonstração da nova perspectiva do Direito vista sob o âmbito da pós positividade e a ascensão dos princípios como portadores de aplicabilidade direta nos conflitos, é indispensável a divisão de tais princípios em duas grandes classes: os instrumentais e os materiais.

A argumentação jurídica, principalmente a constitucional, é formada por dois conjuntos de princípios: o primeiro, é composto de princípios instrumentais ou específicos de interpretação constitucional; o segundo, por princípios materiais propriamente ditos, que trazem em si a carga ideológica, axiológica e finalística da ordem constitucional. Ambas as categorias de princípios orientam a atividade do intérprete, de tal maneira que, diante de várias soluções igualmente plausíveis, deverá ele percorrer o caminho ditado pelos princípios instrumentais e realizar, tão intensamente quanto possível, à luz dos outros elementos em questão, o estado ideal pretendido pelos princípios materiais (BARROSO, 2002, p. 107).

Os princípios instrumentais se referem às diretas ações dos princípios nas práticas jurídicas, estando vinculados exatamente aos procedimentos que são realizados conforme as regras deles oriundas.

Diferente do embasamento filosófico-social, tais princípios visam à construção de uma relação de equivalência e segurança processual no processo de aplicação dos valores de justiça neles baseados.

Os princípios instrumentais não sendo fundamentais, buscam a melhoria do uso e dos resultados do processo e que, por conseguinte, podem ser considerados com maior ou menor amplitude, aceitando graduações várias de acordo com as circunstâncias concretas e os objetivos que desejam que sejam alcançados (NOBRE JUNIOR, 1998, p. 66).

Eles, portanto, se referem à consecução da prática processual decorrente dos princípios, sendo, subdivididos em três tipos: princípios de fundamentação, princípios de interpretação e princípios de supressão de lacunas (OLIVEIRA, 2006).

Os princípios de fundamentação estabelecem o instrumento de construção normativa formado por uma função com duas ordens fundamentais: uma ordem derrogatória e uma outra de qualidade diretiva. 
A ordem derrogatória diz exatamente que toda e qualquer norma que for contrária ao regramento do princípio, automaticamente, perderá a vigência, sendo anteposta em uma hierarquia de inferioridade em relação àqueles.

Já a ordem diretiva se refere necessariamente à orientação intransigente que o aplicador da norma, bem como o legislador deve ter ao construir uma regra de direito, no sentido de que esta deverá ser dirigida necessariamente pelos preceitos oriundos dos princípios.

Quanto à função fundamentadora: os princípios desempenham a função de fundamentação da ordem jurídica, gozando de eficácia derrogatória e diretiva. Derrogatória na medida em que as regras que se contraponham à sua orientação carecerão de vigência, e diretiva na medida em que havendo antinomia entre regras e princípios, aquelas perderão a sua validade. Ou seja, o direito encontra o seu esteio nos princípios gerais do direito (OLIVEIRA, 2006).

Os princípios de interpretação se referem exatamente ao direcionamento dos conflitos normativos conforme os valores previamente fixados pelos princípios de Direito.

$\mathrm{Na}$ medida em que os princípios atuarem na solução de conflitos eles estarão, automaticamente, construindo uma relação com o ordenamento jurídico, complementando o caráter legislativo perante a aplicação normativa indireta.

O desempenho na solução de controvérsia constrói a própria existência normativa no sentido pós positivista.

Quanto à função interpretativa: os princípios desempenham, no plano de solução dos problemas constitucionais, o papel de vetores para soluções ótimas e juridicamente adequadas, na medida em que as controvérsias serão solucionadas com fundamento nas normas que desempenham o papel de fundamentação do próprio ordenamento jurídico (OLIVEIRA, 2006).

Por fim, os princípios de supressão de lacunas referem-se ao processo de suplementação do Direito quando sua "cortina de regras" não esteja devidamente contínua.

Já amparado pela perspectiva positivista, a supressão de lacunas, no pós positivismo, estará vinculada exatamente com a reconstrução normativo-axiológica, ou seja, não é mais apenas a combinação de uma norma com outra, mas a aplicação dos princípios exatamente nas falhas percebidas na lei. 
Quanto à função supletiva: neste caso, desempenham os princípios o mesmo papel que lhes reservou o positivismo jurídico, na medida em que servirão para a colmatação de lacunas no ordenamento jurídico, impedindo a adoção de decisões non liquet (OLIVEIRA, 2006).

Assim, devido ao seu caráter geral, os princípios complementarão com facilidade o processo normativo.

\section{Princípios materiais}

Enquanto os "princípios instrumentais" se referem exatamente àquelas ações jurídicas intimamente ligadas à prática processual e à construção prática jurídico-positiva, os princípios materiais se referem aos sustentáculos substanciais da relação jurídica pós positivista.

Três são os princípios materiais fundamentais do direito visto no âmbito pós positivista: o princípio da noção e resguardo da pessoa humana, a defesa da dignidade e a extensão interpretativa do princípio da legalidade.

O princípio material da valorização pessoa humana é uma das grandes mudanças própria do Direito Pós Positivo, no sentido de que a Constituição Federal, ao preferir a denominação de "pessoa" no lugar de homem ou de cidadão, propôs duas coisas.

Primeiro a valorização do homem como fonte de toda criação jurídica e que, ao mesmo tempo, é o fim para o qual toda norma tem que se dirigir e também a igualdade total entre homens e mulheres, independente de raça, credo ou ideologia.

Segundo, sabe-se que a palavra "pessoa humana" é de natureza neutra, servindo para qualquer elemento do gênero humano e, no sentido semântico, é muito mais apropriada que o termo "homem".

O primeiro aspecto pauta-se no resguardo da pessoa humana que fundamenta o direito no sentido da presença intransigente de propostas materiais cuja sentença depende de toda decisão da vontade do homem necessariamente, negando a leitura positivista que valorizava de forma exagerada a "vontade da lei".

As normas, antes atreladas apenas ao aspecto técnico, e, por isso, chamadas de "programáticas" têm que ser revistas quando se coloca o ideal de pessoa humana como seu principal fim. 
Nesta acepção, a proclamação da normatividade do princípio da dignidade da pessoa humana, na maioria das Constituições contemporâneas, acarretou ao reconhecimento dos princípios como normas fundamentais de todo o sistema jurídico, afastando-se a concepção de programaticidade, que justificava a neutralização da eficácia dos valores e fins norteadores dos sistemas constitucionais (GRAU, 2002, p. 97).

Gofredo Telles Júnior (2003, p. 145-154) mostrou que, no mundo contemporâneo, cada vez mais, o homem vem deixando sua posição estática cujo conceito é previamente delineado por uma norma fixa e passa a influir axiologicamente, construindo o direito e, principalmente, construindo a si mesmo.

O segundo princípio material se refere ao resguardo da dignidade humana que é entendida exatamente como a capacidade do homem valorizar a si mesmo na figura do próximo.

A noção de dignidade, na perspectiva positivista, era apenas fundada no respeito pela norma sendo que o seguimento de uma regra positivamente válida, em teoria, já pressuporia a noção de dignidade pautada na consideração positiva do próximo.

Sabe-se, contudo, que nem sempre o seguimento perfeito de uma regra gera um resultado positivo para o próximo.

Diferente disto, muitas vezes, é na ação contra legem que se dá o respeito pelo outro, já que a norma instituída pode não ter aplicação positiva direta por estar ultrapassada ou por estar apenas atendendo a interesses avessos à noção de justiça ou ao interesse público.

Neste sentido, o direito pós positivo releu a perspectiva de "dignidade humana", buscando uma interpretação além do que é instituído pelas regras normativas, passando a se relacionar de forma direta com relação a vontade e com os princípios.

A dignidade humana, apesar de ter sido um conceito que foi absorvido pela leitura dogmática dos positivistas que a comparava como resultado natural do seguimento positivo da lei, não está efetivamente restrita à lei ou aos preceitos normativos. No pós positivismo, percebe-se que uma tomada de consciência que tente relacionar os anseios e desejos humanos com o respeito pela capacidade de criação e de orientação do próximo passa a superar determinações que classifico como 'fragmentárias', pois se tentarmos entender a noção de justo apenas pela perspectiva legal, estamos claramente fazendo uma análise restritiva que, tal qual um fragmento, apenas dá uma resposta incompleta (TELLES JUNIOR, 2003, p. 145154). 
O último princípio é o da extensão interpretativa da legalidade e pode ser entendido como sendo o unificador dos outros dois princípios acima determinados.

\begin{abstract}
Quando o jurista, percebe que uma lei não está de acordo com a valorização da pessoa humana ou conforme a dignidade no sentido pós positivo desta palavra, ele deve empreender uma modificação desta lei. Deve modificar sua essência, suprimindo partes que considera indesejáveis e, até mesmo, estendendo sua aplicação para esferas que não foram previamente determinadas pelo legislador. Esta "alteração" da lei não significa sua destruição, mas revela a união entre a norma e aquele que dela faz parte, mostrando que não existe separação entre o sujeito e a lei, mas uma necessária complementaridade: cada um dá sentido existencial para o outro. Não há lei sem pessoa humana e não há pessoa humana sem uma lei que por ele foi criada e, nesse sentido, por ele seja respeitada (TELLES JUNIOR, 2003, p. 145-154).
\end{abstract}

Isto porque, na verdade, o princípio de interpretação extensiva se refere à necessidade do jurista interpretar a lei para além de seus aparentes objetivos, buscando uma análise reflexiva da recepção que esta terá na sociedade.

Os princípios, ao apregoar valores ou indicar fins a serem alcançados pelo Estado e pela sociedade, espalham-se pelo sistema, interagem entre si e pautam a atuação dos órgãos de poder, inclusive a do Judiciário na determinação do sentido das normas (BARROSO, 2002, p.177).

Uma lei não pode ser simplesmente aplicada porque sua estrutura formal esteja perfeitamente construída tal qual ocorria no período positivista, mas, ao contrário, os dois princípios fundamentais acima determinados exigem que o intérprete proponha uma leitura prévia dos "resultados sociais" e, principalmente, da recepção de tal norma na sociedade.

Neste sentido, deve-se pensar exatamente que, após uma análise que busque tanto a valorização da pessoa humana (primeiro princípio material) quanto a busca pela dignidade (segunda princípio material), o jurista deve estender a aplicação legal, "forçando" uma interpretação da lei adequada.

Por fim, vale ressaltar em todas as relações públicas e privadas o princípio da dignidade da pessoa humana ( $\mathrm{CF}$ art. $1^{\circ}, \mathrm{III}$ ), que se tornou o centro axiológico da concepção de Estado democrático de direito e de uma ordem mundial idealmente pautada pelos direitos fundamentais (AVILA, 2005, p. 75).

Enfim, o princípio da dignidade da pessoa humana identifica um momento de integridade moral a ser assegurado a todas as pessoas por sua só existência no mundo. É 
uma relação de respeito junto à criação, involuntariamente da crença que se confessa quanto à sua origem. A dignidade está relacionada tanto com a liberdade e valores do espírito como com as condições materiais de subsistência. Não tem sido bucólico, entretanto, o empenho para consentir que o princípio transite de uma dimensão ética e abstrata para as motivações racionais e fundamentadas das decisões judiciais (AVILA, 2005, p. 76).

A livre interpretação normativa não é "livre" no sentido de que o jurista possa fazer tudo que lhe aprazer, mas, ao contrário, este deve seguir um caminho bem claro no projeto de construção do Direito:

Primeiro, deve buscar os fins da norma conforme os dois princípios materiais acima sustentados: a dignidade e a pessoa humana e, após este projeto, deve estender a atuação da lei, modificando-a, alterando seus institutos e, muitas vezes, criando uma relação de geral complementaridade entre fato, norma e pessoa.

\section{Considerações finais}

A explanação constitucional tradicional está fundamentada em um arquétipo de regras, justapostas mediante subsunção, competindo ao intérprete o papel de revelar o sentido das normas e fazê-las incidir no caso concreto. As circunspeções que formula são de fato, e não de valor. Por conseguinte, não lhe viabiliza função criativa do Direito, porém apenas uma atividade de conhecimento técnico. Esta probabilidade convencional ainda permanece de grande valimento na solução de boa parte dos problemas jurídicos, contudo nem sempre é satisfatório para lidar com as questões constitucionais, notadamente a colisão de direitos fundamentais.

A Constituição Federal de 1988 fez uma inovação ao constituir a dignidade da pessoa humana como um valor basilar do Estado Democrático de Direito, dando-Ihe potência máxima através do princípio da capacidade imediata das leis. Os direitos da personalidade, estabelecidos na dignidade da pessoa humana representam um valor fundamental, unitário e ilimitado do atual ordenamento jurídico. Este caracteriza-se como intransmissíveis, irrenunciáveis, imprescritíveis e oponíveis erga omnes, nos termos nos artigos 11 à 21 do Código Civil de 2002. Compreendida a personalidade humana com valor atenta-se para a importância da elasticidade de sua tutela. 
Nesse sentido o direito pós positivo pode ser entendido como o ato de gerir socialmente o direito que é baseado em ações dirigidas pelos fundamentais princípios constitucionais em sentido amplo, resultando na construção de elementos normativos vinculados à colocação de princípios na prática jurídica, reintroduzindo as idéias de justiça e legitimidade ao ordenamento jurídico.

\section{Referências}

ÁVILA, Humberto. Teoria dos princípios. São Paulo: Editora Malheiros, 2005.

BARCELLOS Ana Paula de. A Eficácia Jurídica dos Princípios Constitucionais. Renovar, 2002.

BARROSO, Luis Roberto. A Nova Interpretação Constitucional-Ponderação, direitos fundamentais e relações privadas. Rio de Janeiro: Renovar, 2003.

BARROSO, Luis Roberto. Temas de direito constitucional. São Paulo: Saraiva, 2002.

BONAVIDES, Paulo. Direito Constitucional. 13. ed. São Paulo: Editora Malheiros, 2001.

CANOTILHO, José Joaquim Gomes. Teoria da Constituição. Coimbra: Almedina, 1998.

. Teoria da Constituição. ed. rev. Coimbra: Almedina, 2000.

GRAU, Eros Roberto. Ensaio e discurso sobre a interpretação / aplicação do direito. São Paulo: Malheiros, 2002.

GUIMARÃES, Luiz Carlos Forghieri. Princípios Constitucionais e o Supremo Tribunal Federal. Disponível em: <www2.oabsp.org.br/asp/esa/comunicacao/esa1.2.3.1.asp?id_noticias=87>. Acesso em: jun. 2006.

NERY JUNIOR, Nelson. Princípios de processo civil na Constituição Federal. 7. ed. rev. e atual. São Paulo: Editora Revista dos Tribunais, 2002.

NOBRE, JÚNIOR. A proteção contratual no código do consumidor e o âmbito de sua aplicação. Revista de Direito do Consumidor, n. 27, jul./set. 1998. 
OLIVEIRA, Marcus Vinícius Xavier de. Os princípios reitores do direito público e do direito privado e o princípio da autonomia da vontade regrada. Disponível em: <http:// jus2. uol . com.br/doutrina/ texto.asp?id=3871>. Acesso em: jun. 2006.

TELLES JÚNIOR, Goffredo. O Direito Quântico. São paulo: Ed Juarez de Oliveira, 2003. 
